Bioscientia Medicina: Journal of Biomedicine \& Translational Research

Journal Homepage: www.bioscmed.com

\title{
Recurrence Prediction Score of the Localy Advance Breast Cancer in West Sumatera Province, Indonesia
}

\author{
Shinta Qorina ${ }^{1 *}$, Wirsma Arif Harahap ${ }^{2}$, Ricvan Dana Nindrea ${ }^{2,3}$
}

${ }^{1}$ Surgical Division Faculty of Medicine Universitas Andalas/ Dr. M Djamil General Hospital Padang, West Sumatera Province, Indonesia.

${ }^{2}$ Surgical Oncology Division Faculty of Medicine Universitas Andalas/ Dr. M Djamil General Hospital Padang, West Sumatera Province, Indonesia.

${ }^{3}$ Doctoral Program, Faculty of Medicine, Public Health and Nursing, Universitas Gadjah Mada, Yogyakarta City, Indonesia.

\section{A R T I C L E I N F O \\ Keywords: \\ Breast Cancer \\ Locally Advance \\ Prognosis Factor \\ *Corresponding author: \\ Shinta Qorina \\ E-mail address: \\ shintaqorina@gmail.com}

All authors have reviewed and approved the final version of the manuscript.

https://doi.org/10.32539/bsm.v5i9.406

\begin{abstract}
A B S T R A C T
Background: Breast cancer is the most common malignancy that occurs in women in the world, which is about $18 \%$ of cancer cases that occur in women. Every year there are 1 million new cases of breast cancer worldwide and nearly 60,000 patients die from this disease. Therefore, the authors want to find out more about the prognosis factors that play a role in influencing the survival of patients with locally advanced breast cancer in Padang city, West Sumatera Province Indonesia. Methods: This study is a retrospective case-control study of locally advanced breast cancer for patients in Padang city. The study was conducted at the Surgical Oncology Division of Dr. M Djamil Padang Hospital, Ropana Suri Hospital, Ibnu Sina Hospital and Siti Rahmah Padang Hospital from September 2018 to December 2018. The total number of samples for the two groups was 242 people. The sampling technique used was convenience sampling. Results: In this study 4 prognostic factors were found that had a significant effect on predicting breast cancer recurrence, namely histopathological type, stage, regional lymph and lymphovascular invasion with $\mathrm{p}<0.05$. Conclusion: Prognosis factors that influence breast cancer recurrence are histopathological type, stage, regional lymph node status and lymphovascular invasion. A scoring system is obtained that is good enough to predict the possibility of breast cancer recurrence.
\end{abstract}

\section{Introduction}

Breast malignancy is the most malignant disease that occurs in women in the world, which is about $18 \%$ of cancer cases that occur in women. Every year there are 1 million new cases of breast cancer worldwide and nearly 60,000 patients die from this disease. In the United States, there are 600,000 cases per year, in other developed countries there are 350,000 cases and in developing countries, there are 250,000 cases per year ${ }^{1}$.

Breast cancer is the fifth most common cause of cancer deaths worldwide (after lung, stomach, liver, and colon cancer). Locally advanced breast cancer (LABC) is included in advanced breast cancer. Clinical appearance of advanced breast cancer is characterized by tumour enlargement $>5 \mathrm{~cm}$, with the involvement of the skin and on the chest wall accompanied by From the description above, prognostic factors that involvement of the axillary lymph node or internal mammary gland and supraclavicular gland. Advancedlocal breast cancer is divided into stadium IIIA, IIIB, and IIIC which refers to American Joint Committee for Cancer Staging 20171,2.

Prognosis factors of locally advanced breast cancer patients include age, tumour size, number of axillary lymph node involvement, histopathology type, histology type, hormonal status and expression of HER-2 and several other factors ${ }^{3,4}$.

From the description above, prognostic factors that affect survival in patients with advanced breast cancer can be formulated. Therefore, the author wants to find out more about the prognosis factors that play a role in influencing the survival of patients with advanced breast cancer in the city of Padang.

affect survival in patients with advanced breast cancer 


\section{Materials and methods}

This research is a retrospective case-control study of locally advanced breast cancer patients in the city of Padang. The study was conducted at the Surgical Oncology Division of Dr. M Djamil Padang Hospital, Ropana Suri Hospital, Ibnu Sina Hospital and Siti Rahmah Padang Hospital from August 2018 to December 2018.

The population of the study was breast cancer patients diagnosed with locally advanced breast cancer who were admitted to Dr.M.Djamil Padang Hospital, Ropana Suri Hospital, Ibnu Sina Hospital, Siti Rahmah Hospital in 2010-2017.

The sample size was calculated with a certain formula and a minimum sample size of 66 people was obtained for each group. The number of samples for both groups was 132 people. The sampling technique used was convenience sampling.

The inclusion criteria were patients with advanced stage breast cancer who were treated at Dr.M.Djamil Padang Hospital, Ropana Suri Hospital, Ibnu Sina Hospital, and Siti Rahmah Hospital. Immunohistochemical examinations (estrogen receptors, progesterone receptors, and HER-2 / Neu) were carried out and patients agreed to participate in this study. Exclusion criteria were patients with incomplete data.

The variables of this study consisted of independent variables such as age, tumour size, axillary lymph nodes, histopathological type, histopathological grading, ER, PR, HER-2, Ki67, subtype, LVI, and cancer stage, while the dependent variable was either recurrence or no recurrence of the disease

\section{Results}

The relationship between the prognosis factors with the recurrence of patients with locally advanced breast cancer in the city of Padang can be seen in table 1 below.

Table 1. Relationship between the prognosis factors with the recurrence of patients with locally advanced breast cancer in the city of Padang

\begin{tabular}{|c|c|c|c|}
\hline \multirow{3}{*}{ Variable } & \multicolumn{2}{|c|}{ Recurrence } & \multirow{3}{*}{ p-value } \\
\hline & & & \\
\hline & $\begin{array}{l}\text { Recurrence (f/\%) } \\
(n=56)\end{array}$ & $\begin{array}{l}\text { No Recurrence (f/\%) } \\
(\mathrm{n}=186)\end{array}$ & \\
\hline \multicolumn{4}{|l|}{ Age } \\
\hline$<50$ year & $36(64.3)$ & $112(60.2)$ & 0.695 \\
\hline$\geq 50$ year & $20(35.7)$ & $74(39.8)$ & \\
\hline \multicolumn{4}{|l|}{ Histopathology } \\
\hline Invasive ductal & $51(91.1)$ & $145(78.0)$ & $0.046^{*}$ \\
\hline Invasive lobular & $5(8.9)$ & $41(22.0)$ & \\
\hline \multicolumn{4}{|l|}{ Tumour Size } \\
\hline$<5 \mathrm{~cm}$ & $3(5.4)$ & $5(2.7)$ & 0.391 \\
\hline$\geq 5 \mathrm{~cm}$ & 53 (94.6) & $181(97.3)$ & \\
\hline \multicolumn{4}{|l|}{ Lymph Node Status } \\
\hline$\geq 1$ & $55(98.2)$ & $164(88.2)$ & $0.047^{*}$ \\
\hline 0 & $1(1.8)$ & $22(11.8)$ & \\
\hline \multicolumn{4}{|l|}{ Estrogen receptors } \\
\hline Negative & 33 (58.9) & $113(60.8)$ & 0.929 \\
\hline Positive & $23(41.1)$ & $73(39.2)$ & \\
\hline \multicolumn{4}{|l|}{ Progesteron receptors } \\
\hline Negative & $29(51.8)$ & $86(46.2)$ & 0.564 \\
\hline Positive & 27 (48.2) & $100(53.8)$ & \\
\hline \multicolumn{4}{|l|}{ HER2 } \\
\hline Negative & $37(66.1)$ & $126(67.7)$ & 0.943 \\
\hline Positive & 19 (33.9) & $60(32.3)$ & \\
\hline \multicolumn{4}{|l|}{ Subtype } \\
\hline Luminal & $32(57.1)$ & $116(62.4)$ & 0.585 \\
\hline Non luminal & 24 (42.9) & $70(37.6)$ & \\
\hline \multicolumn{4}{|l|}{ KI67 } \\
\hline$<20$ & $14(25.0)$ & 49 (26.3) & 0.978 \\
\hline$\geq 20$ & $42(75.0)$ & 137 (73.7) & \\
\hline \multicolumn{4}{|l|}{ Type } \\
\hline $\mathrm{Bad}$ & $4(7.1)$ & $12(6.5)$ & 0.768 \\
\hline Good & 52 (92.9) & 174 (93.5) & \\
\hline \multicolumn{4}{|l|}{ Stages } \\
\hline IIIB-IIIC & $41(73.2)$ & 109 (58.6) & $0.049^{*}$ \\
\hline IIIA & $15(26.8)$ & $77(41.4)$ & \\
\hline \multicolumn{4}{|l|}{ LVI } \\
\hline Negative & $52(92.9)$ & $159(85.5)$ & 0.223 \\
\hline Positive & $4(7.1)$ & $27(14.5)$ & \\
\hline
\end{tabular}

Note: ${ }^{*} \mathrm{p}<0.05$, there is a significant relationship 
There was relationship between histopathological, nodular, or cancer staging with the recurrence of patients with locally advanced breast cancer in the city of Padang $(\mathrm{p}<0.05)$. However, there was no relationship between age, tumour size, estrogen receptor, progesterone receptor, HER2, luminal, KI67, cancer types, or LVI with the recurrence of patients with locally advanced breast cancer in Padang City ( $p>0.05)$.

The selection of candidate variables to predict recurrence of patients with locally advanced breast cancer can be seen in table 2 below.

Table 2. The selection of candidate variables to predict the recurrence of patients with locally advanced-stage breast cancer

\begin{tabular}{lcc}
\hline \multicolumn{1}{c}{ Variable } & OR $(95 \% \mathrm{CI})$ & $p$-value \\
\hline Age & $1.18(0.63-2.21)$ & 0,695 \\
Histopathology & $2.88(1.08-7.69)$ & $0.046^{\dagger}$ \\
Tumour Size & $2.05(0.47-8.86)$ & 0.391 \\
Lymph Node Status & $7.37(0.97-56.01)$ & $0.047^{\dagger}$ \\
Stages & $1.93(0.99-3.73)$ & $0.049^{\dagger}$ \\
Estrogen receptor & $0.93(0.50-1.70)$ & 0.929 \\
Progesteron receptor & $1.24(0.69-2.27)$ & 0.564 \\
HER 2 & $0.93(0.49-1.75)$ & 0.943 \\
Subtype & $0.81(0.44-1.48)$ & 0.585 \\
Ki-67 & $0.93(0.47-1.85)$ & 0.978 \\
LVI & $2.21(0.74-6.60)$ & $0.223^{\dagger}$ \\
\hline $\mathrm{p}<0.25$, included as the candidate variable &
\end{tabular}

Based on table 2, it can be concluded that the variables which predictors for determining recurrence of locally advanced breast cancer patients were histopathology, nodules, stage and LVI ( $\mathrm{p}<0.25)$. In predicting the recurrence of patients with advanced breast cancer, the risk calculation has been performed using multiple logistic regression with the HosmerLemeshow Test approach.

The calculation of risk to predict the recurrence of patients with locally advanced breast cancer can be known as follows.

Table 3. Calculation of risk to predict the recurrence of patients with locally advanced stage breast cancer

\begin{tabular}{lccccc}
\hline \multicolumn{1}{c}{ Variable } & B & S.E & B/ S.E & B / S.E / 1.15 & Fulfilled \\
\hline $\begin{array}{l}\text { Histopathology } \\
\text { (Invasive ductal) }\end{array}$ & 1.13 & 0.51 & 2.24 & 1.93 & 2 \\
Stages (IIIB-IIIC) & & & & & 1.00 \\
Lymph Node Status ( $\geq 1)$ & 0.45 & 0.39 & 1.15 & 1.06 & 1 \\
LVI (positive) & 0.46 & 0.37 & 1.22 & 1.41 & 1 \\
\hline $\begin{array}{l}\text { Hosmer-Lemeshow test } \\
\text { B= beta; SE= standard error }\end{array}$ & 0.92 & 0.56 & 1.63 & &
\end{tabular}

Based on table 3, it is known that the minimum score of the risk calculation is 1 and the maximum score is 5 .

In determining the sensitivity and specificity of scoring to predict the odds of recurrence in patients with locally advanced breast cancer, the cut-off points from score calculations in subjects who have experienced the recurrence within the patients with locally advanced breast cancer has been determined and can be seen in Figure 1 and Table 4. 


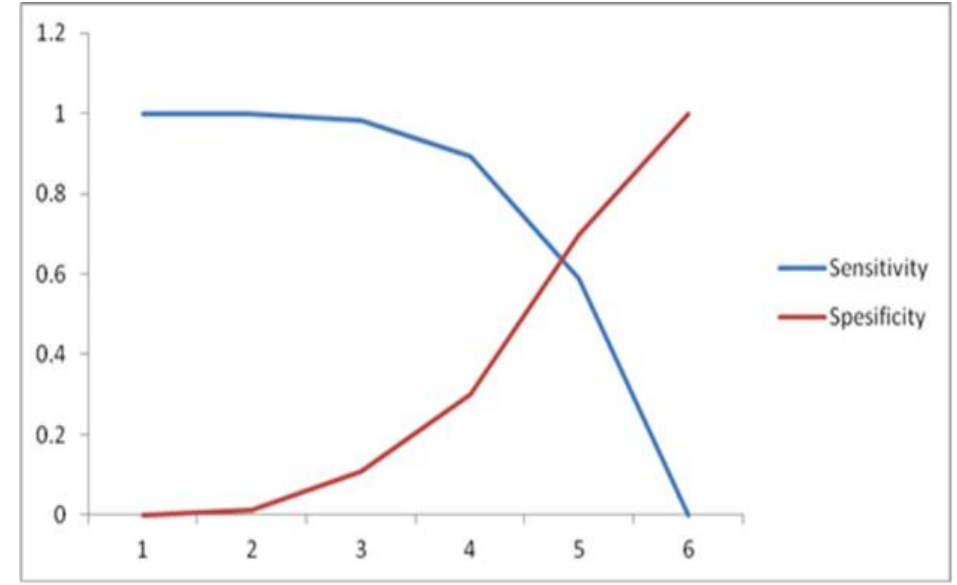

Figure 1. Cut-off point of sensitivity and specificity according to receiver operating characteristic analysis

In figure 1 , it is known that the optimal cut-off point on the intersection of the sensitivity and specificity lines is at the cut-off point 5 . The cut-off point value of the optimal intersection point of the sensitivity and specificity lines can be seen in table 4 .

Table 4. Cut off points based on sensitivity and specificity in predicting the recurrence in patients with localized advanced-stage breast cancer

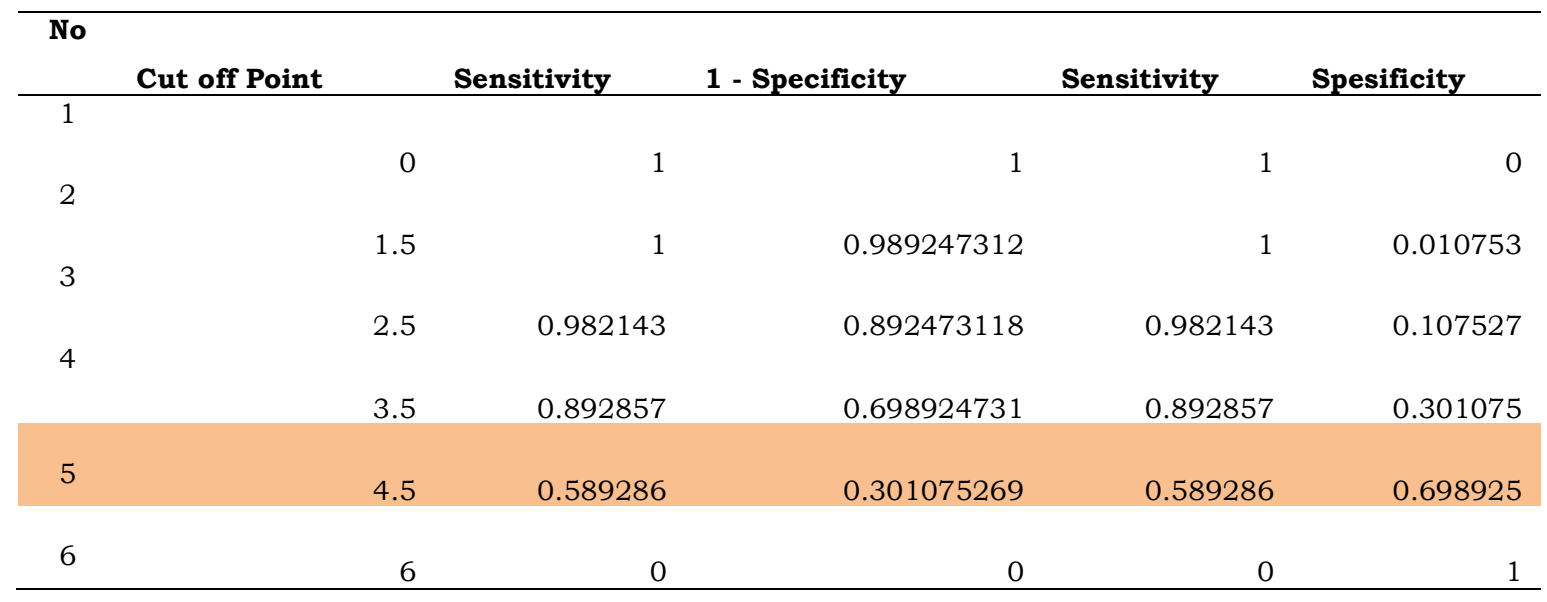

Table 4 shows that the value of cut-off point in predicting the recurrence of patients with locally advanced breast cancer is at the cut-off point 4.5 (fulfilled 5), so the classification can be explained as follows:

Subjects in patients with locally advanced breast cancer experience recurrence if they have a score of $\geq$ 5. Subjects in patients with locally advanced breast cancer do not experience recurrence if they have a score of $<5$.

The determination of this classification has a sensitivity of $58.9 \%$ and specificity of $69.8 \%$. The accuracy of the scoring obtained in predicting the recurrence of patients with locally advanced breast cancer can be seen in Figure 2 below. 


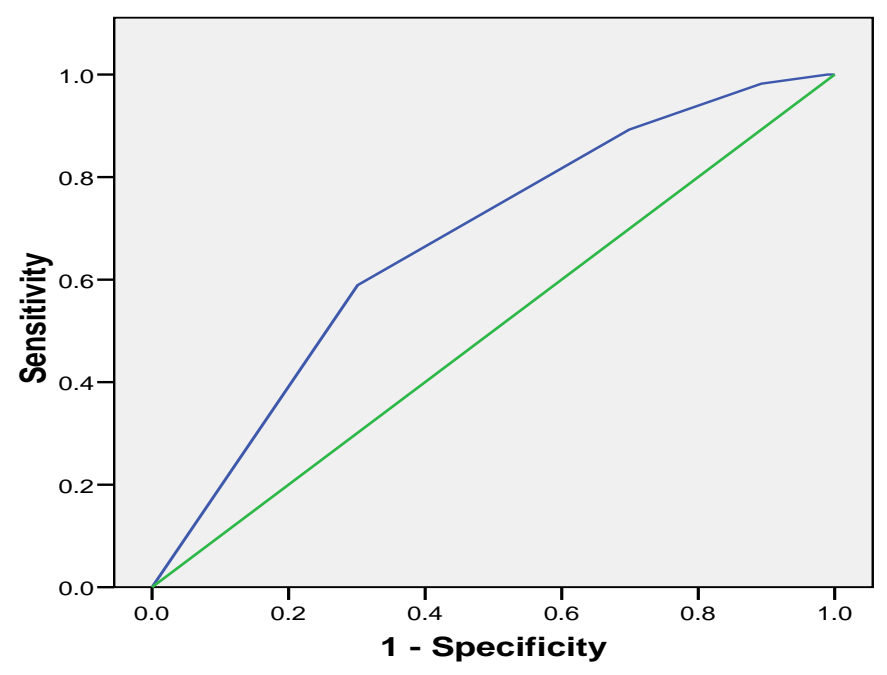

Diagonal segments are produced by ties.

Figure 2. The accuracy of scoring to predict the recurrence in patients with locally advanced stage breast cancer

Based on the receiver operating curve (ROC) analysis, it has an area under curve (AUC) value of

\section{Discussion}

In this study, 4 prognostic factors that have a significant effect on predicting breast cancer recurrence were found, which were histopathological types, regional lymph node status, stages, and LVI with $\mathrm{p}<0.05$. According to the histopathological type, the invasive ductal type has the recurrence rate of $91.1 \%$ and the lobular invasive type has 8.9\%. Whereas according to lymph node status, there was a recurrence of $98.2 \%$ in lymph node status > 1 and $1.8 \%$ in lymph node status $=0$.

While according to the stages, there were $26.8 \%$ stage IIIA recurrence rates and $73.2 \%$ stage IIIB-IIIC. Another variable that was significant for disease recurrence was the lymphovascular invasion. The results of this study found the recurrence rates of the positive lymphovascular invasion was $92.9 \%$ and negative lymphovascular was $7.1 \%$. With the sensitivity of $58.9 \%$ and specificity of $69.8 \%$ and an accuracy of $67.2 \%$. Whereas other prognosis factors, namely age, tumour size, histopathology types, ER, PR, HER-2, Ki67 and subtypes were not very significant in predicting recurrence in breast cancer $(p>0.05)$.
$67.2 \%$ which is quite good in the accuracy category.

The degree of histopathology in breast cancer was divided into good and bad differentiation. As in previous studies, the degree of histopathological differentiation was the risk factor for breast cancer, so it can be said that the higher the degree of histopathological differentiation, the higher the risk of breast cancer recurrence ${ }^{5}$.

Furthermore, the type of histopathology was one of the many important prognostic factors. The results of histopathological examination of breast cancer were referred to the diagnostic standard determined by WHO in 20126. In this study the type of carcinoma was divided into 2 major groups namely: 1) Ductal carcinoma, which consisted of invasive ductal carcinoma, invasive NST carcinoma, infiltrating ductal carcinoma, glycogen-rich cell carcinoma, and metaplastic carcinoma. This group was a group of breast carcinoma with a poor prognosis. 2) Non-ductal carcinoma, which has a good prognosis including invasive lobular carcinoma, mucous carcinoma, papillary carcinoma and breast adenocarcinoma. This situation will affect the prognosis of HER2 positive-3 breast cancer.

Based on the research in Europe found the degree 
of middle-to-poor differentiation of HER2 positive-3 breast cancer as much as $92.1 \%[7,8]$. This was related to the age of the subjects, most of whom were patients with premenopausal age. This situation made the prognosis of HER2 +3 breast cancer patients in Indonesia worse because besides the sufferer came with advanced stage, the degree of differentiation was also bad.

Hormonal status of receptors has an important role in estimating recurrence in breast cancer. The research conducted by Cheng et.al. in 20,027 breast cancer patients from 1991-1997 and followed up for 10 years found that the recurrence associated with the hormonal status of receptors and stages was highest in negative hormonal status in all stages of breast cancer. In patients with negative hormone receptors, hazard values rose sharply and were statistically highest in the first 5 years after therapy.

Besides hormonal, Ki67 and HER 2 also influence breast cancer recurrence. According to Taneja P et al., Ki67's over-expression of more than $20-50 \%$ was a high risk of the recurrent of the disease. In accordance with the study of Jeong S et al., The high expression of Ki67 was associated with a poor prognosis in patients with breast cancer with shortened disease-free survival and overall survival.

The molecular subtype of breast cancer has been shown to determine the location of distant metastases in organs because it has the ability to metastasize far away in certain organs such as bone. Patients who experienced bone metastases were found to have more of the luminal subtype. Luminal A subtype was very rare to metastasize to lung organs. Meanwhile, relapse in the pleura, although rare, showed both subtypes of luminal. In breast cancer with basal subtypes, due to up-regulation of the WNT signal, it metastasized more frequently to the brain. There was a relationship between the rate of recurrence and stages and the recurrence of breast cancer. Stage I showed a lower recurrence rate compared to stage II - III cancers. Patients with stage III breast cancer statistically showed the highest hazard rate compared to stage I $(\mathrm{P}$ $<0.01)$ followed by stage II $(\mathrm{P}<0.01)$. Recurrence rates were statistically higher in the younger age group $(\mathrm{P}$
$<0.01)$.

Based on the tools, we can determine the prediction of whether there will be a recurrence of breast cancer or not. It can be described again based on table 3 that the histopathological type of ductal invasive breast cancer has a score of 2 . In the stages variable, there is a score of 1 in patients with stage IIIB-IIIC. Furthermore, regional lymph node status variables have a score of 1 . The invasion lymphovascular variables have a score of 1 . From the 4 variables that have a significant effect, it can be summed that the value is 5 . According to the cut-off, a value of $<5$ states that there is no risk of recurrence and if the value $\geq 5$, the risk of recurrence is high, with the sensitivity of $58.9 \%$ (good enough) and specificity of $69.8 \%$ and accuracy of $67.2 \%$. Therefore, it can be concluded that histopathological type, regional lymph node status, stage, and lymphovascular invasion can predict the possibility of recurrence in breast cancer. While other factors, namely tumour size, histopathology types, ER, PR, HER-2, Ki67 and subtypes cannot be seen as predictors for predicting the recurrence of breast cancer.

After conducting a multivariate analysis, several alternative models will be obtained. For each model, we can know the quality of each model based on statistics (calibration and discrimination) and clinical. Calibration is defined to be good if the p-value in the calibration test (Hosmer and Lemeshow) is greater than 0.05. Discrimination is defined to be good if the discriminant value of the receiver operating curve (ROC) analysis has an area under curve (AUC) value greater than or equal to the expected AUC value. As clinical model, it is defined to be good if the model is capable of managing the disease. The chosen model is a model that has good calibration and discrimination and is capable of managing the disease.

In this study, we obtained a prediction model to estimate the likelihood of recurrence of breast cancer using histopathological type factors, regional lymph node status, stages, and lymphovascular invasion so that the possibility of the recurrence of breast cancer can be estimated by assessing these factors. In this study, there were 4 influential factors to estimate the 
possibility of recurrence. These factors were the type of histopathology, regional lymph node status, stages, and lymphovascular invasion. So that only by knowing these factors, we can find out whether a breast cancer sufferer will experience recurrence later on.

\section{References}

1. Nindrea RD, Aryandono T, Lazuardi L. Breast cancer risk from modifiable and nonmodifiable risk factors among women in Southeast Asia: a meta-analysis. Asian Pac J Cancer Prev 2017; 18: 3201-6.

2. American Cancer Institute. Breast cancer fact and figure 2015. American Cancer Society, Surveillance Research, 2015.

3. Rustogi A, Brudrukkar A, Dinshaw K, et al. Management of locally advanced breast cancer: Evolution and current practice. JCRT. 2000; 1(1): 21-30.

4. Rakha EA, El-Sayed ME, Green AR. Prognostic markers in triple-negative breast cancer. Cancer. 2007;109: 25-32.

5. Galea M, Blamey R, Elston C, et al. The Nottingham prognostic index in primary breast cancer. Breast Cancer Research and Treatment. 1997; 22: 207-19.

6. Garne JP, Aspergren K. Primary prognostic factors in invasive breast cancer with special reference to ductal carcinoma and histologic malignancy jenis. Cancer. 1993; 73:1438-48.

7. Shenvkier T, Weir L, Levine M. Clinical practice guidelines for the care and treatment of breast cancer: Treatment for women with stage III or locally advanced breast cancer. CAMJ. 2004; 70: 983-94

8. Clark GM. Prognosis and predictive factors. In: Harris Jr, Lippman ME, Morrow M, Osborn CK. Disease of the breast. Second Ed. Philadelphia: Lippincot Williams \& Walkins. 2000; 489-508. 